\title{
Acesso lexical e processamento fonológico na dislexia do desenvolvimento
}

\author{
Lexical access and phonological processing in \\ developmental dyslexia
}

\author{
Clara Oliveira Esteves \\ Universidade Federal do Rio de Janeiro - UFRJ \\ Christina Abreu Gomes \\ Universidade Federal do Rio de Janeiro - UFRJ
}

\section{Resumo}

Diversas pesquisas têm demonstrado que crianças disléxicas apresentam déficits na busca de palavras em diferentes tipos de teste. Assume-se que as dificuldades em acessar as foras das palavras estão relacionadas a deficiências na codoficação fonológica (FAUST, 2003), embora não haja menção na literatura sobre problemas na performance espontânea de crianças disléxicas em relação à forma das palavras que elas produzem. Neste artigo argumentamos que o problema da codificação fonológica e do acesso é mais bem tratado nos Modelos baseados no Uso, que concebem o conhecimento fonológico em diferentes estratos de abstração. De acordo com os resultados obtidos, parece que as crianças disléxicas acessam os padrões fonológicos mais abstratos da palavra-alvo embora a forma sonora da palavra não esteja, em alguns casos, disponível.

Palavras-chave

Dislexia, Acesso lexical, Modelos baseados no Uso 


\section{Abstract}

Extensive research has shown that dyslexic children have word finding deficits in different types of tests. It is generally assumed that the difficulties in accessing the word forms are related to deficiencies in phonological encoding (FAUST, 2003), although there is no mention in the literature about problems in the spontaneous performance of dyslexic children in terms of the word-forms they produce. In this paper we argue that the problem of phonological encoding and access is better handled in a usage-based model that conceives implicit phonological knowledge as a ladder of abstraction. According to the results obtained, it seems that dyslexic children access the more abstract phonological pattern of the target word although the word-form is in same cases unattainable.

\section{Keywords}

Dyslexia, Word Access, Usage-Based Model 


\section{Introdução}

ma questão primordial para a teoria linguística é identificar de que maneira os falantes estabelecem representações abstratas das formas sonoras das palavras no léxico e como acessam essas representações na produção e percepção. As diversas teorias fonológicas surgidas ao longo do percurso do pensamento linguístico desde o estruturalismo diferem, entre outras coisas, em relação ao grau de abstração dessas representações, aos níveis de representação e aos primitivos de representação.

As contribuições dos estudos para a discussão dessas questões se utilizam tanto de dados de indivíduos normais, isto é, sem patologia associada à linguagem, quanto de população clínica. O presente trabalho tem como objeto de estudo o acesso e a representação das formas sonoras das palavras no léxico em crianças com dislexia do desenvolvimento, cujos resultados foram analisados sob a ótica dos Modelos Multirrepresentacionais da Linguagem. O objetivo é discutir as hipóteses relacionadas à inabilidade das crianças disléxicas na recuperação das formas das palavras em testes de nomeação de figuras, atribuída por diversos autores a déficits de representação fonológica (SWAN; GOSWAMI, 1997; FAUST et al., 2003).

\section{Objeto de estudo e pressupostos teóricos}

A dislexia do desenvolvimento é um transtorno que acomete crianças no processo de alfabetização. De acordo com a definição do Orton Dyslexia Society Research Committee, a dislexia seria um distúrbio específico da linguagem de origem constitucional, caracterizada por dificuldade na decodificação de palavras isoladas, causada por uma ineficiência no processamento da informação fonológica. Ou seja, há uma interrupção no desenvolvimento normal das habilidades necessárias para a aprendizagem da leitura (e, consequentemente, da escrita). Sendo assim, as crianças não conseguem aprender a ler através da 
maneira tradicional. Tais dificuldades na decodificação de palavras são, geralmente, inesperadas em relação à idade e às outras habilidades cognitivas e acadêmicas (em muitos casos, o QI não verbal é maior do que a média); elas não são resultado de um distúrbio geral do desenvolvimento ou de qualquer impedimento sensorial.

Muitas são as hipóteses de etiologias prováveis para esse distúrbio, no entanto a mais aceita hoje em dia é a hipótese do Déficit Fonológico. Em outras palavras, essa dificuldade na decodificação das palavras escritas seria causada por um déficit na representação e/ou acesso às informações da gramática fonológica. No entanto, embora seja consenso entre muitos autores (LIBERMAN et al., 1974; BRADLEY; BRYANT, 1981; SNOWLING, 1981; STANOVICH; SIEGEL, 1994; BOWEY, 1996; MANIS et al., 1997; CAPOVILLA; CAPOVILLA, 2000; RISPENS, 2004; DESROCHES et al., 2006) que crianças disléxicas apresentam tal déficit fonológico, não há uma informação clara na literatura a respeito da natureza desse déficit, sendo difícil estabelecer se tais crianças têm problemas na representação da gramática fonológica ou no processamento dessas informações representadas.

Uma das habilidades que estão relacionadas ao processamento fonológico é a capacidade de recuperar as palavras no léxico. Existe uma literatura ampla que demonstra que crianças disléxicas apresentam dificuldades na recuperação espontânea de palavras (cf. FAUST et al., 2003 para uma revisão bibliográfica) e defende-se que essa dificuldade está relacionada ao déficit fonológico também apresentado por essas crianças. No entanto, novamente, a distinção entre o que seria causado por um problema de representação ou de processamento fonológico não fica claro na literatura. Por exemplo, Swan e Goswami (1997) demonstraram que as crianças disléxicas apresentaram desempenho pior em teste de nomeação de figuras apesar de o tamanho do léxico dessas crianças ser semelhante ao das crianças dos grupos controle. No entanto, os autores concluem que esse desempenho pior pode ser um resultado tanto de déficit de representação como de processamento fonológico, sem, no entanto, achar possível fazer uma distinção entre déficits nesses dois processos, apesar de eles serem, logicamente, dois processos diferentes. Ainda, Esteves e Maia (2008), em estudo sobre crianças disléxicas falantes do português brasileiro, encontraram que crianças disléxicas mostraram diferenças significativas quando comparadas a crianças com desenvolvimento típico em uma tarefa de decisão lexical de palavras reais e pseudopalavras apresentadas auditivamente. $\mathrm{O}$ grupo experimental foi 
significativamente mais lento e apresentou maior percentagem de erro na decisão do que o grupo controle, o que foi interpretado como uma dificuldade na recuperação das palavras no léxico, sem, no entanto, ser possível identificar a natureza dessa dificuldade devido ao tipo de metodologia empregada.

De uma forma geral, a Fonologia Probabilística (PIERREHUMBERT, 2003) - que constitui um dos modelos rotulados como multirrepresentacionais (cf. SILVA e GOMES, 2007) - pressupõe que o conhecimento fonológico é abstraído de forma gradual e em diferentes níveis de representação, por meio de um léxico organizado em redes de conexões. Os falantes teriam representações de características físicas e acústicas dos sons percebidos e produzidos no fluxo de fala; de todo o inventário fonético disponível na língua para a codificação da forma das palavras, incluindo não só os segmentos de fala, mas também aspectos prosódicos e entonacionais, além de toda a informação redundante advinda da distribuição fonética total da língua. A representação sonora das palavras no léxico seriam abstrações sobre a experiência do falante de produzir e ouvir e conteria informação redundante relativa às diversas possibilidades fonéticas disponíveis na experiência do falante. A gramática fonológica, que contém as informações sobre restrições fonotáticas, padrões silábicos, prosódicos, etc, seria abstraída das formas sonoras armazenadas no léxico, da mesma maneira que o nível da representação das relações morfofonológicas.

Neste trabalho, argumenta-se que, sob a ótica dos Modelos Multirrepresentacionais de Linguagem, pode-se pensar na especificação mais detalhada dos "déficits fonológicos" apresentados por crianças disléxicas em termos do acesso aos diferentes níveis de representação que poderiam estar afetados nesse grupo experimental.

Há, portanto, duas questões principais para o presente estudo:

$O$ déficit fonológico descrito como características de sujeitos disléxicos é uma dificuldade de acesso elou representação?

(ii) Quais níveis de representação elou de acesso às informações fonológicas estariam prejudicados nesses sujeitos?

De acordo com o exposto acima, a hipótese deste trabalho é de que os disléxicos possuiriam uma dificuldade específica no acesso à forma sonora das palavras no léxico e não apresentariam déficits representacionais em nenhum dos níveis de representação. Não há na literatura sobre esse grupo nenhuma evidência 
de que crianças disléxicas tenham desempenho diferente de crianças com desenvolvimento típico na fala espontânea no que tange à produção da forma das palavras de acordo com o esperado para sua comunidade de fala.

\section{Metodologia}

Foram avaliados dois grupos de crianças, 11 crianças disléxicas (grupo experimental) e 13 crianças com desenvolvimento típico (grupo controle). Todas as crianças foram submetidas a um Teste de Nomeação de Figuras, elaborado para testar o desempenho das crianças em testes de nomeação tanto em relação ao acesso quanto para se observar o tipo de substituição produzida.

O teste de nomeação consistiu de 36 itens lexicais. As figuras do teste representam palavras que diferem em tamanho e frequência de ocorrência (de token). O conjunto de estímulos está apresentado na TABELA 1, abaixo.

\section{TABELA1}

Estímulos Utilizados no Teste de Nomeação de Figuras e suas Respectivas Frequências de Ocorrência

\begin{tabular}{|c|c|c|c|c|c|c|c|c|c|c|c|}
\hline \multirow{3}{*}{ 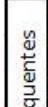 } & Cama: & 6,020 & & Bule: & 95 & & Geladeira & 2,090 & \multirow{3}{*}{ 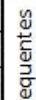 } & \multirow{2}{*}{\begin{tabular}{l|l}
\multirow{2}{*}{} & Pirâmide \\
\end{tabular}} & \multirow{2}{*}{\begin{tabular}{|l|}
188 \\
298 \\
\end{tabular}} \\
\hline & Mesa: & 17,407 & & Leque: & 214 & & Telefone & 32,343 & & & \\
\hline & Maçã & 1,584 & & Jipe: & 132 & 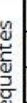 & Pirulito & 169 & & Binóculo & 187 \\
\hline 这 & Bala & 4,819 & 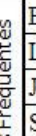 & Sino: & 683 & 感 & Borboleta & 1,161 & $\frac{1}{n}$ & Ferradura & 203 \\
\hline$\frac{n}{n}$ & Mala: & 2,242 & 品 & Lupa: & 290 & $\frac{n}{\pi}$ & Sabonete & 616 & $\stackrel{\circ}{\frac{C}{4}}$ & Alfinete & 155 \\
\hline$\sum_{n}$ & Milho: & 6,188 & $\sum_{n}^{\infty}$ & Rolha: & 183 & 虫 & Televisão & 19,726 & $\sum_{n}$ & Envelope & 975 \\
\hline$\frac{0}{n}$ & Bolo: & 2,947 & 은 & Arpa: & & $\frac{5}{\frac{\pi}{\pi}}$ & Dinossauro & 797 & 을 & Espingarda: & \\
\hline 商 & Vela: & 1,735 & $\frac{\pi}{\bar{n}}$ & Sela: & & $\frac{n}{0}$ & Detetive & 1,917 & 点 & Rinoceronte: & \\
\hline & Gato: & 3,564 & $\overline{0}$ & Iglú: & & 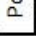 & Escorrega & 214 & $\therefore$ & Espantalho: & \\
\hline
\end{tabular}

Foram 18 palavras dissilábicas e 18 palavras polissilábicas. Metade dos itens de cada categoria de tamanho era de alta frequência de ocorrência e metade de baixa frequência de ocorrência. O tamanho da palavra foi definido em função do número de sílabas, embora o tamanho das palavras seja semelhante também quanto ao número de segmentos para a maioria dos itens de cada categoria. Tomou-se o cuidado de que haja uma divisão clara entre as palavras de menor tamanho - small length (SL) e as de maior tamanho - long length (LL). Por exemplo, os itens SL são todos dissilábicos ao passo que os itens LL são todos de quatro sílabas, com exceção de um item com 5 sílabas. 
A frequência de ocorrência e o vocabulário das crianças foram considerados na seleção dos itens lexicais a serem examinados. A contagem de frequência de ocorrência dos itens foi obtida de um corpus de 130 milhões de palavras e os itens foram agrupados em duas categorias de alta e baixa frequência (www.projetoaspa.org). O Projeto ASPA - Avaliação Sonora do Português Atual -é fruto de um trabalho desenvolvido na Universidade Federal de Minas Gerais, com o intuito de construir um conhecimento probabilístico sólido a respeito da estrutura do Português Brasileiro contemporâneo. Além da frequência de ocorrência, tomou-se o cuidado de garantir também a familiaridade das palavras para a faixa etária das crianças avaliadas. Para tanto, foram consultados dois instrumentos de terapia e avaliação de linguagem infantil, a saber Fixação de Fonemas e Palavras (SERRANO, s/d) e ABFW - Teste de Linguagem Infantil (DE ANDRADE et al., 2000). Sendo assim, algumas palavras que apresentaram baixa frequência no corpus do projeto ASPA, por serem bastante familiares no universo infantil, foram classificadas como palavras de alta frequência (por exemplo, "pirulito" e "escorrega"). Além disso, um teste piloto com as palavras selecionadas por meio desses instrumentos de avaliação e terapia em combinação com o corpus do Projeto ASPA confirmou que todas as figuras eram familiares às crianças da mesma idade do grupo experimental e controle.

$\mathrm{Na}$ aplicação do teste, as crianças eram instruídas a olhar cada figura e dizer o nome do objeto. Se elas não apresentavam a resposta esperada, eram encorajadas a tentar novamente e uma sequência de pistas semânticas e fonológicas eram apresentadas pela entrevistadora, sempre nesta ordem. Todas as tentativas de busca da forma da palavra assim com o tipo de pista que elas utilizaram para acessar o item foram computadas. Esse procedimento tinha como objetivo elicitar o estado de tip-of-the-tong (TOT), seguindo o paradigma experimental de TOT usado em diversas pesquisas. Essa metodologia de testagem foi escolhida porque procedimentos para estudo dos déficits de nomeação, geralmente, medem a velocidade de nomeação, e fornecem respostas do tipo "tudo-ou-nada", disponibilizando pouca ou nenhuma informação sobre os processos subjacentes à habilidade principal investigada. Diferentemente, $o$ paradigma adotado neste trabalho se baseia no estudo qualitativo sobre o que os falantes podem saber e dizer em relação ao item lexical quando eles estão vivenciando um breakdown temporário na recuperação deste item. Assim, podese inferir sobre a natureza multidimensional da palavra, assim como sobre o papel 
dessas diferentes informações linguísticas no acesso lexical. Portanto, o estado TOT fornece um meio de isolar o processamento fonológico dentro de uma tarefa que é conceitualmente impulsionada (FAUST et al., 2003).

A aplicação do teste foi gravada na íntegra em aparelho digital SONY NWD-B103F para que essas informações pudessem ser posteriormente levantadas, quantificadas e analisadas.

Além do Teste de Nomeação de Figuras, também foram aplicados o Peabody Picture Vocabulary Test (DUNN \& DUNN, 1997), versão traduzida para o português, a fim de controlar o tamanho do léxico das crianças do grupo controle e do grupo experimental e o Teste de Leitura de Pseudopalavras (ANEXO I), com o objetivo de caracterizar a diferença de habilidade de leitura entre os dois grupos de crianças e entre as crianças do mesmo grupo, e não diagnosticar as crianças do grupo experimental, uma vez que essas já possuíam diagnóstico estabelecido em clínicas fonoaudiológicas do Rio de Janeiro, obtido por meio de uma bateria de testes padronizados. O teste Peabodyé um teste de compreensão que visa quantificar o conhecimento do vocabulário em crianças (a partir de 2 anos e meio) e adultos. Este teste ainda não está padronizado no Brasil, mas existe uma pesquisa sendo realizada por Capovilla (1997) para padronização para o português brasileiro. Este teste é utilizado como referência para os trabalhos em linguística sobre aquisição e população clínica infantil (FERREIRA, 2007, BECKMAN, EDWARD; MUNSON, 2007). O teste de vocabulário receptivo consiste de uma série de pranchas que especificam um total de 244 vocábulos, cada qual contendo quatro gravuras diferentes. Para cada prancha, a criança é solicitada a identificar e apontar a gravura que melhor representa o significado da palavra enunciada pelo examinador. Após a identificação da base e o teto para cada criança, obtémse o escore padronizado pelo teste e verifica-se a conformidade ou não do desempenho da criança com a sua idade. $O$ teste foi administrado conforme as instruções especificadas no manual.

\section{Análise dos resultados}

Antes de iniciarmos a descrição dos resultados, é importante salientar que houve a exclusão de uma das crianças do grupo experimental por ter apresentado um comportamento muito similar ao das crianças do grupo controle no teste de nomeação se distanciando das crianças do seu grupo. Sendo assim, o grupo experimental totalizou 10 crianças e o grupo controle 13 na fase de análise dos dados. 
O Teste de Leitura de Pseudopalavras e o Teste de Vocabulário Receptivo Peabody III foram utilizados a fim de determinar e fazer uma comparação inter- e intragrupos - sobre o nível de leitura e o tamanho do léxico, respectivamente, embora as crianças disléxicas já tivessem sido diagnosticadas de acordo com testes padronizados, como já mencionado anteriormente. Para analisar a diferença de desempenho de ambos os grupos nos dois testes, utilizamos o teste estatístico Qui-quadrado ( $X$-squared). Os resultados obtidos em ambos os testes estão apresentados a seguir na TABELA 2:

TABELA2

Valores Médios dos Testes de Vocabulário e de Leitura

\begin{tabular}{l|ccc}
\hline & $\begin{array}{c}\text { DISLÉXICOS } \\
\text { PADR } \tilde{A} \boldsymbol{O}\end{array}$ & CONTROLES & ESCORE \\
\hline Teste de Vocabulário & 126,3 & 119,7 & 122 \\
Teste de Leitura & 13,1 & 23,9 & 24 \\
\hline
\end{tabular}

Com relação ao Teste de Leitura de Pseudopalavras, o grupo de disléxicos obteve um desempenho significativamente pior do que o grupo controle, como era de se esperar $(X$-squared $=828, \mathrm{df}=10, \mathrm{p}$-value $<2.2 \mathrm{e}-16)$; de um escore total de 24 pontos, o grupo experimental alcançou uma média de 13,1 pontos, enquanto o grupo controle alcançou uma média de 23,9 pontos.

Já no Teste de Vocabulário Receptivo Peabody III, o grupo de disléxicos apresentou um desempenho melhor do que o grupo experimental, sendo essa diferença também estatisticamente significativa $(X$-squared $=681.5077, \mathrm{df}=18$, p-value $<2.2 \mathrm{e}-16$ ). Este teste fornece um escore padrão esperado para cada idade, sendo a faixa etária, de ambos os grupos, equivalente ao escore de 112. O grupo experimental apresentou na média um escore de 126,3, enquanto o grupo controle apresentou um escore de 119,7.

Esse resultado sobre o tamanho do léxico remete a um dos pressupostos teóricos da Fonologia Probabilística, de que o conhecimento linguístico implícito do falante é resultado de inferências probabilísticas de padrões fonológicos estabelecidos a partir das palavras armazenadas em seu léxico. Assim, pode-se pensar que quanto mais adequado for o tamanho do léxico da criança em relação ao esperado em termos de aquisição e idade, em função do conjunto de formas sonoras de palavras que o falante possuir armazenadas em seu léxico, mais inferências probabilísticas, abstrações e generalizações a 
respeito do sistema fonológico da língua ela poderá fazer, e, portanto, estabelecer as representações fonológicas adequadas, sendo estas cada vez mais robustas. Portanto, uma vez que as crianças disléxicas apresentaram um tamanho de léxico maior do que as crianças do grupo controle, pode ser plausível supor que elas não deveriam apresentar déficits representacionais em nenhum nível de abstração. $\mathrm{E}$, se as crianças disléxicas não apresentam dificuldades em abstrair essas informações, é de se esperar que sua gramática fonológica, utilizada para codificar novos itens armazenados, não seja diferente da gramática das crianças com desenvolvimento típico de mesma idade e, portanto, que elas não apresentem déficit na representação da forma sonora dos itens no léxico.

Na aplicação do teste de nomeação, em conjunto, os resultados obtidos estão em conformidade com outros trabalhos como Faust et al.(2003) e Swan e Goswami (1997), que também encontraram nos disléxicos uma dificuldade significativa em recuperar as palavras no léxico em testes de nomeação de figuras. Os primeiros autores interpretaram essa dificuldade na recuperação da forma fonológica das palavras como um déficit na representação fonológica dessas palavras. Já Swam e Goswami (1997) concluíram que essa dificuldade pode ser um resultado tanto de déficit de representação como de processamento fonológico, conforme mencionado anteriormente.

Os resultados indicaram que as crianças do grupo experimental apresentaram desempenho significativamente pior do que as crianças do grupo controle, tanto nas respostas iniciais, como nas respostas finais do teste de nomeação de figuras, conforme pode ser observado na TABELA 3. Esse resultado sugere uma dificuldade na recuperação das palavras no léxico.

TABELA 3

Tipos de Respostas Iniciais e Finais de Ambos os Grupos

\begin{tabular}{l|ccc|ccc}
\hline & \multicolumn{3}{|c|}{ DISLÉXICOS } & \multicolumn{3}{c}{ CONTROLE } \\
\hline & Correta & Incorreta & Sem Resp & Correta & Incorreta & Sem Resp \\
\cline { 2 - 7 } Resposta Inicial & $66,70 \%$ & $17,50 \%$ & $15,80 \%$ & $86,30 \%$ & $7,50 \%$ & $6,20 \%$ \\
Resposta Final & $83,90 \%$ & $6,90 \%$ & $9,20 \%$ & $95,70 \%$ & $0 \%$ & $4,30 \%$ \\
\hline
\end{tabular}

Apesar de haver diferentes níveis de leitura entre os disléxicos e diferentes tamanhos de léxico tanto entre disléxicos como entre os controles, para ambos os grupos, não foi observada nenhuma relação entre tipo de resposta inicial (TRI) e nível de leitura $(\mathrm{X}$-squared $=1.1258, \mathrm{df}=2, \mathrm{p}$-value $=0.5695$, para o grupo 
controle $X$-squared $=19.594, \mathrm{df}=16, \mathrm{p}$-value $=0.2391$, para o grupo experimental), assim como não foi observada nenhuma relação entre TRI e tamanho de léxico $(\mathrm{X}$-squared $=12.743, \mathrm{df}=20, \mathrm{p}$-value $=0.8881$, para o grupo controle $\mathrm{e}$ $\mathrm{X}$-squared $=20.68, \mathrm{df}=18, \mathrm{p}$-value $=0.2959$, para o grupo experimental), evidenciando uma independência entre essas variáveis. Isso significa que nem o nível de leitura nem o tamanho do léxico foram fortes preditores para o desempenho das crianças no teste de nomeação de figuras.

Swan \& Goswami (1997) obtiveram resultados semelhantes no que diz ao tamanho do léxico das crianças: as autoras não encontraram nenhuma diferença entre o vocabulário receptivo das crianças disléxicas e seus pares em nível de leitura e em idade cronológica. Essa diferença apenas se manifestou em relação ao grupo de maus leitores não disléxicos, cujo vocabulário receptivo se encontrava empobrecido.

Os efeitos de frequência de ocorrência das palavras do teste e de tamanho foram analisados para as respostas iniciais.

Quanto ao efeito de frequência de ocorrência das palavras do teste, é esperado que palavras de alta frequência sejam mais fáceis de serem acessadas, já que a representação das palavras no léxico se torna mais robusta de acordo com a quantidade de tokens à qual o falante é exposto, tornando essa representação mais disponível para o acesso. Os resultados, apresentados nos GRÁFICOS 1 e 2 a seguir, mostram que, para ambos os grupos, foram encontrados efeitos de frequência de ocorrência; as palavras menos frequentes foram mais suscetíveis a substituições do que as palavras mais frequentes, confirmando as expectativas.

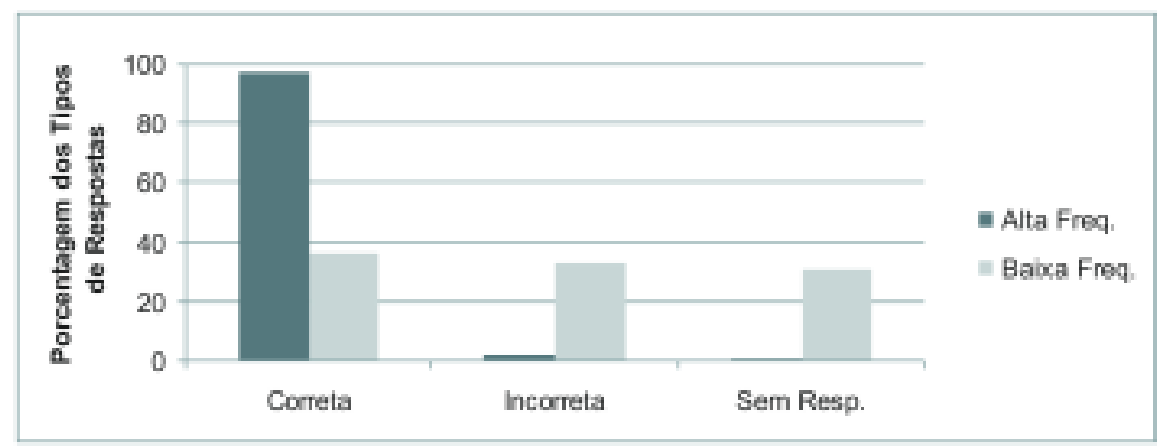

GRÁFICO 1: Tipo de Respostas X Frequência da Palavra - Disléxicos 


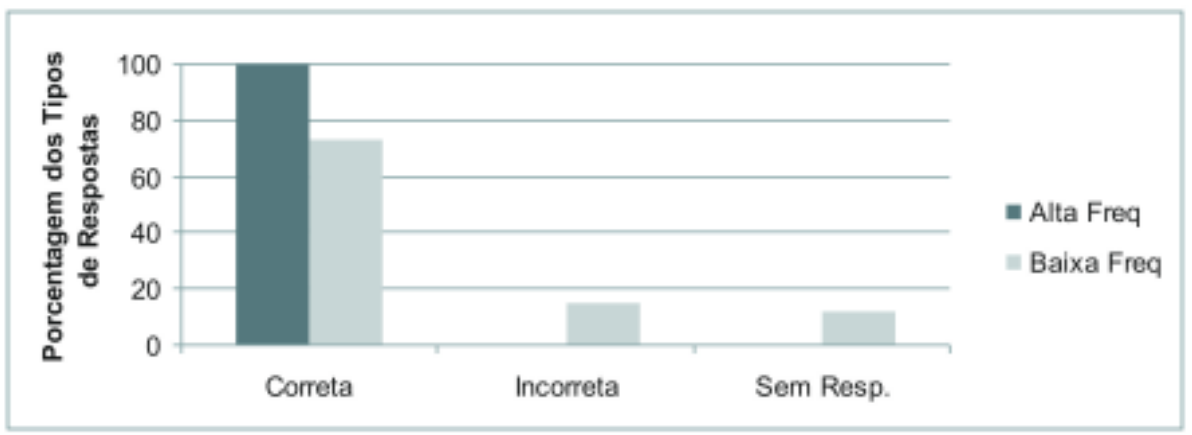

GRÁFICO 2: Tipo de Respostas X Frequência da Palavra - Controles

Com relação ao grupo experimental, a relação entre tipo de resposta e frequência foi estatisticamente significativa $(X$-squared $=151.2688, \mathrm{df}=2$, p-value $<2.2 \mathrm{e}-16)$. Para as palavras de alta frequência, o total de respostas corretas foi de 175 (97\%), e três respostas incorretas e dois itens sem resposta, enquanto, para as palavras de baixa frequência, o resultado foi de 65 respostas corretas, 60 respostas incorretas e 55 itens sem respostas.

Para as palavras de alta frequência, o grupo controle obteve um total de $234(100 \%)$ de respostas corretas e nenhuma resposta incorreta ou não resposta, enquanto, para as palavras de baixa frequência, o resultado foi 170 respostas corretas, 35 respostas incorretas e 29 itens sem respostas. Essa diferença entre palavras de alta frequência e palavras de baixa frequência para o grupo controle foi estatisticamente significativa $(X$-squared $=74.1386, \mathrm{df}=2$, $\mathrm{p}$-value $<2.2 \mathrm{e}-16$ ).

Com relação ao tamanho do item (dissílabos x polissílabos), é de se esperar que palavras mais compridas sejam mais difíceis de serem acessadas uma vez que elas são fonologicamente mais complexas por apresentarem mais segmentos. Especificamente, quando se trata de sujeitos disléxicos, espera-se que esse efeito seja ainda maior devido a sua dificuldade no processamento fonológico. Esse efeito foi encontrado, por exemplo, no trabalho de Swan \& Goswami (1997), no qual, dos quatro grupos de crianças, apenas o grupo de disléxicos apresentou efeito de comprimento.

No entanto, no presente estudo, obtivemos resultados curiosos: foi observado sim um efeito de tamanho de palavra para o grupo controle (X-squared $=9.463, \mathrm{df}=2, \mathrm{p}$-value $=0.008813$, no entanto, no sentido contrário ao que seria 
esperado, ou seja, as palavras dissílabas foram mais suscetíveis a substituições do que as polissílabas, enquanto o esperado seria o contrário. Eles acertaram uma total de 192 (82\%) itens dissílabos, enquanto o total de acertos para itens polissílabos foi maior: 212 (91\%). Esse efeito não foi observado para o grupo experimental $(\mathrm{X}$-squared $=2.7068, \mathrm{df}=2, \mathrm{p}$-value $=0.2584$ ), isso é, não houve diferença entre o tipo de resposta para palavras dissílabas ou polissílabas. Uma possível explicação para esses resultados fora do esperado seria que todas as palavras (dissílabos e polissílabos) eram formadas por um mesmo tipo silábico (CV) que, por sua vez, é o tipo silábico mais frequente no português brasileiro. Sendo assim, talvez a complexidade fonológica entre as palavras de diferentes tamanhos não tenha sido suficiente para resultar em diferenças significativas. Portanto, seria interessante associar outra variável como "tipo silábico" ou "frequência de tipo silábico", por exemplo, à variável "tamanho de palavra" em estudos posteriores.

\subsection{Natureza das substituições}

Todas as respostas incorretas obtidas neste teste foram analisadas a fim de verificar qual a natureza das substituições realizadas tanto por disléxicos como por controles quando eles não conseguiram acessar a forma correta das palavras. A TABELA 4 resume esses resultados.

TABELA4

Tipos de Substituições de Ambos os Grupos

\begin{tabular}{l|ccc}
\hline & DISLÉXICOS & CONTROLES & P-valor \\
\hline Semântica & $37(58,7 \%)$ & $19(52,8 \%)$ & $=0.7158$ \\
Fonológica & $9(14,3 \%)$ & $8(22,2 \%)$ & $=0.4652$ \\
Outras & $17(27 \%)$ & $9(25 \%)$ & $=1.0000$ \\
Total & $63(100 \%)$ & $36(100 \%)$ & - \\
\hline
\end{tabular}

Os dados mostraram que, analisando as substituições intragrupos, todas as crianças de ambos os grupos realizaram mais substituições semânticas (por exemplo, harpa por violão) nas respostas iniciais, do que substituições fonológicas (por exemplo, rolha por rodo) e substituições de outros tipos, que não tinham nenhuma relação aparente com o alvo (por exemplo, cogumelo por prego $)(\mathrm{X}$-squared $=894.3658, \mathrm{df}=6, \mathrm{p}$-value $<0.0001$ para o grupo controle, 
e X-squared $=844.6543, \mathrm{df}=6, \mathrm{p}$-value $<0.0001$, para o grupo experimental). Além disso, se compararmos as substituições intergrupos, podemos notar que, proporcionalmente, a quantidade de substituições semânticas realizadas por ambos os grupos não se diferenciou de forma estatisticamente significativa (X-squared $=0.1325, \mathrm{df}=1, \mathrm{p}$-value $=0.7158$ ), assim como de substituições fonológicas $(\mathrm{X}$-squared $=0.5333, \mathrm{df}=1, \mathrm{p}$-value $=0.4652)$, indo de encontro aos resultados de Faust et al., que encontraram que crianças disléxicas cometeram mais substituições fonológicas e semânticas do que o grupo controle quando experienciavam o estado TOT. Na presente pesquisa, as substituições realizadas pelo grupo experimental não se diferenciaram daquelas realizadas pelo grupo controle em relação ao tipo, mas sim em relação à quantidade.

Para o grupo controle, as substituições semânticas corresponderam a um total de 58,7\% das respostas incorretas, enquanto as substituições fonológicas somaram um total de 14,3\% e outras substituições, $27 \%$. Já o grupo experimental realizou 52,8\% de substituições semânticas, 22,2\% de substituições fonológicas e $25 \%$ de outras substituições.

Ainda, todas as substituições fonológicas de ambos os grupos foram analisadas a fim de verificar o grau de similaridade entre as produções das crianças e a palavra-alvo. É importante ressaltar que, nesta análise, foram consideradas as pseudopalavras fonologicamente semelhantes que foram produzidas pelas crianças do grupo experimental. Apesar de serem em pequeno número, é interessante analisar as suas características, uma vez que elas podem revelar o tipo de informação fonológica que está sendo acessada. A TABELA 5 a seguir apresenta as substituições classificadas quanto à natureza e ao grupo a que pertence cada criança.

TABELA5

Exemplos de Substituições Fonológicas de Ambos os Grupos

\begin{tabular}{l|ccl}
\hline \multirow{2}{*}{ ESTÍMULO } & SUBSTITUIÇÃO & TIPO & GRUPO \\
\hline \multirow{2}{*}{ Bule } & Chalé & Outras & Disléxico \\
& Chale & Outras (Mista) & Disléxico \\
& Xícara & Semântica & Disléxico \\
& Chaleira & Semântica & Controle \\
\hline \multirow{2}{*}{ Leque } & Legue & Pseudopalavra & Disléxico \\
& Abanador & Semântica & Controle \\
& Chalé & Fonológica & Controle \\
& Jaleco & Fonológica & Controle \\
\hline
\end{tabular}




\begin{tabular}{|c|c|c|c|}
\hline Jipe & Carro & Semântica & Disléxico \\
\hline Lupa & $\begin{array}{c}\text { Lente } \\
\text { Telescópio } \\
\text { Aumentador } \\
\text { Lente de Aumento }\end{array}$ & $\begin{array}{l}\text { Semântica } \\
\text { Semântica } \\
\text { Semântica } \\
\text { Semântica }\end{array}$ & $\begin{array}{l}\text { Disléxico } \\
\text { Disléxico } \\
\text { Controle } \\
\text { Controle }\end{array}$ \\
\hline Rolha & $\begin{array}{c}\text { Bulha } \\
\text { Chuveiro } \\
\text { Tampa } \\
\text { Rodo } \\
\text { Pote } \\
\text { Água } \\
\text { Rosca }\end{array}$ & $\begin{array}{c}\text { Pseudopalavra } \\
\text { Outras } \\
\text { Semântica } \\
\text { Fonológica } \\
\text { Outras } \\
\text { Outras } \\
\text { Fonológica } \\
\end{array}$ & $\begin{array}{l}\text { Disléxico } \\
\text { Disléxico } \\
\text { Disléxico } \\
\text { Disléxico } \\
\text { Disléxico } \\
\text { Disléxico } \\
\text { Controle }\end{array}$ \\
\hline Harpa & $\begin{array}{c}\text { Rena } \\
\text { Piano } \\
\text { Arca } \\
\text { Violão } \\
\text { Viola }\end{array}$ & $\begin{array}{c}\text { Outras } \\
\text { Semântica } \\
\text { Pseudopalavra } \\
\text { Semântica } \\
\text { Semântica }\end{array}$ & $\begin{array}{l}\text { Disléxico } \\
\text { Disléxico } \\
\text { Disléxico } \\
\text { Disléxico } \\
\text { Controle }\end{array}$ \\
\hline Sela & $\begin{array}{c}\text { Fivela } \\
\text { Armadura }\end{array}$ & $\begin{array}{c}\text { Fonológica } \\
\text { Semântica }\end{array}$ & $\begin{array}{l}\text { Disléxico } \\
\text { Controle }\end{array}$ \\
\hline Iglu & $\begin{array}{c}\text { Cabana } \\
\text { Iblu } \\
\text { Casa de Gelo } \\
\text { Igluru } \\
\text { Caverna } \\
\text { Cubo de Gelo }\end{array}$ & $\begin{array}{c}\text { Semântica } \\
\text { Pseudopalavra } \\
\text { Semântica } \\
\text { Pseudopalavra } \\
\text { Semântica } \\
\text { Semântica } \\
\end{array}$ & $\begin{array}{l}\text { Disléxico } \\
\text { Disléxico } \\
\text { Disléxico } \\
\text { Disléxico } \\
\text { Controle } \\
\text { Controle } \\
\end{array}$ \\
\hline Detetive & $\begin{array}{c}\text { Investigador } \\
\text { Homem Estranho }\end{array}$ & $\begin{array}{c}\text { Semântica } \\
\text { Outras }\end{array}$ & $\begin{array}{l}\text { Disléxico } \\
\text { Disléxico }\end{array}$ \\
\hline Pirâmide & Montanha & Outras & DIS e CON \\
\hline Cogumelo & $\begin{array}{c}\text { Comida Mexicana } \\
\text { Tampa } \\
\text { Prego }\end{array}$ & $\begin{array}{l}\text { Semântica } \\
\text { Outros } \\
\text { Outros }\end{array}$ & $\begin{array}{l}\text { Disléxico } \\
\text { Disléxico } \\
\text { Controle }\end{array}$ \\
\hline Binóculo & Telescópio & Semântica & Disléxico \\
\hline Ferradura & $\begin{array}{c}\text { Ímã } \\
\text { Ferro }\end{array}$ & $\begin{array}{c}\text { Outros } \\
\text { Fonológica }\end{array}$ & $\begin{array}{l}\text { Disléxico } \\
\text { Controle }\end{array}$ \\
\hline Alfinete & $\begin{array}{l}\text { Grampo } \\
\text { Alface }\end{array}$ & $\begin{array}{c}\text { Outras } \\
\text { Fonológica }\end{array}$ & $\begin{array}{l}\text { Disléxico } \\
\text { Disléxico }\end{array}$ \\
\hline Envelope & Carta & Semântica & DIS e CON \\
\hline
\end{tabular}




\begin{tabular}{l|ccc}
\hline \multirow{2}{*}{ Espingarda } & Pistola & Semântica & Disléxico \\
& Arma & Semântica & DIS e CON \\
\hline \multirow{2}{*}{ Rinoceronte } & Eceronte & Fonológica & Disléxico \\
& Minotauro & Semântica & Disléxico \\
& Hipopótamo & Semântica & Disléxico \\
\hline \multirow{2}{*}{ Espantalho } & Boneco de Palha & Semântica & Disléxico \\
& Espantador & Outras (Mista) & Disléxico \\
\hline
\end{tabular}

As substituições fonológicas fornecidas por ambos os grupos foram variadas e apresentaram diferentes graus de similaridade em relação às palavrasalvo correspondentes.

Foi possível observar a produção tanto de palavras reais como de pseudopalavras (por exemplo, ['ahkə] para harpa; ['legi] para leque ou [i'blu] para iglu). Essas respostas mantiveram a maioria dos segmentos da palavra-alvo, tal como segmentos iniciais ou finais emudaram apenas um, o qual manteve algum detalhamento fonético fino do segmento-alvo, tal como ponto ou modo de articulação, sonoridade; nesses casos, outros aspectos da palavra-alvo se mantiveram, tal como o número de segmentos da palavra e o número e tipo de sílabas. Algumas dessas substituições diferiram em tamanho, porém mantiveram alguns segmentos e o acento silábico da palavra-alvo (por exemplo, [ese'rôt $\int \mathrm{I}$ ] para rinoceronte);

Algumas outras substituições mantiveram menos características em comum com os alvos, mantendo apenas os segmentos iniciais, como em [aw'fası] para alfinete ou ['hodv] para rolha; outras mantiveram apenas os segmentos finais, como em [fi'velə] para sela ou ['buKə] para rolha, ou mediais, como [3a'leku] para leque. Foram observados alguns acréscimos de segmentos, como em [i'gluru] para iglu, e também omissões de segmentos, como em [ese'rõt $\int \mathrm{I}$ ] para rinoceronte.

Importante ressaltar que, apesar de as crianças do grupo controle fornecerem menos substituições fonológicas para serem analisadas do que as crianças do grupo experimental, ainda sim foi possível observar que essas substituições não diferiram significativamente nas suas características. Em outras palavras, as substituições apresentadas pelos dois grupos compartilhavam a natureza da informação fonológica presente nelas, evidenciando que eles puderam acessar o mesmo tipo de informação, a saber, o padrão fonológico mais abstrato da palavra-alvo e o detalhamento fonético, embora a forma exata dessas mesmas palavras se encontre completa ou parcialmente inatingível. Esses dados parecem também confirmar a organização do léxico em redes de similaridades, uma vez que foi possível observar a ativação da vizinhança fonológica de algumas palavras. 


\section{Considerações finais}

O objetivo deste trabalho foi investigar a natureza da inabilidade para recuperação de palavras apresentada por crianças com dislexia do desenvolvimento, respondendo a duas questões principais: (i) $O$ déficit fonológico descrito como características de sujeitos disléxicos é uma dificuldade de acesso ou de representação? (ii) Quais níveis de representação elou de acesso às informações fonológicas estariam prejudicados nesses sujeitos? Nesta seção será feita, portanto, uma síntese de todos os achados a fim de tentar responder a essas questões, confirmando ou refutando as hipóteses iniciais.

Em conjunto, os resultados apresentados estão em conformidade com outros trabalhos como o de Faust et al. (2003) e de Swan e Goswami (1997), que encontraram nos disléxicos uma dificuldade significativa em recuperar as palavras no léxico em testes de nomeação de figuras. Os primeiros autores interpretaram essa dificuldade na recuperação da forma fonológica das palavras como um déficit na representação fonológica dessas palavras. Já Swam e Goswami (1997) concluíram que essa dificuldade pode ser um resultado tanto de déficit de representação como de processamento fonológico, no entanto os autores não acham possível fazer uma distinção entre déficits nesses dois processos, apesar de eles serem, logicamente, dois processos diferentes.

No entanto, argumentamos que, tomando por base os pressupostos dos Modelos Multirrepresentacionais, podemos explicar melhor o desempenho das crianças com dislexia na tarefa de nomeação.

Primeiramente, as crianças disléxicas realmente mostraram um desempenho significativamente pior do que as crianças do grupo controle, tanto nas respostas iniciais como nas respostas finais do teste de nomeação de figuras. Isto, por si só, sugere uma dificuldade na recuperação das palavras no léxico, mas não esclarece se essa dificuldade ocorre porque há um déficit de representação dessas palavras no léxico mental, ou porque há um impedimento no processamento dessas informações. No entanto, o desempenho superior das crianças com dislexia no teste de vocabulário receptivo em conjunto com o benefício que essas crianças mostraram ter com as pistas semânticas e fonológicas fornecidas pelo examinador ao longo do teste de nomeação parecem indicar que elas não apresentam nenhuma dificuldade na representação das palavras em seu léxico, apesar de o acesso a essas representações estar prejudicado. De fato, de acordo com os pressupostos teóricos da Fonologia Probabilística, não há razão para esperar que 
uma criança não tenha condições de fazer as abstrações necessárias para a representação da forma sonora das palavras. Portanto, pode-se pensar que, já que as crianças do grupo experimental apresentaram um escore maior do que o grupo controle no teste de vocabulário receptivo, elas não deveriam apresentar dificuldades em abstrair as informações fonológicas a partir das palavras armazenadas nos seus léxicos, aparentemente, íntegros e, assim, representar a gramática fonológica. E, ainda, o fato de elas terem recuperado posteriormente a forma de algumas das palavras-alvo mostra que a forma sonora estava representada, no entanto a criança não foi capaz de acessá-la rapidamente.

Em segundo lugar, não observamos diferença entre os grupos nem em relação ao tipo de substituição apresentada pelas crianças nas respostas iniciais, nem em relação ao grau de similaridade fonológica entre a produção da criança e a palavra-alvo. Ambos os grupos apresentaram mais substituições semânticas do que fonológicas e, em relação à natureza das substituições fonológicas, para ambos os grupos, elas evidenciaram preservação da representação de alguma informação fonológica abstrata da forma da palavra, assim como da informação fonética fina, apesar de o acesso à forma da palavra no léxico se apresentar dificultado, principalmente nas palavras de baixa frequência. Portanto, essa similaridade entre as substituições realizadas por disléxicos e controles apontam para um desempenho qualitativamente semelhante entre os grupos, estando a diferença entre os grupos no grau de dificuldade que disléxicos apresentam no processamento dessas informações fonológicas representadas a fim de recuperá-las do léxico.

Ainda, analisando a natureza das informações fonológicas recuperadas pelo grupo experimental, podemos perceber que algumas respostas mantiveram a maioria dos segmentos da palavra-alvo, tal como segmentos iniciais ou finais e mudaram apenas um, o qual manteve algum detalhamento fonético fino do segmento-alvo, tal como ponto ou modo de articulação; nesses casos, outros aspectos da palavra-alvo se mantiveram, tal como o número de segmentos da palavra e o número e tipo de sílabas. Algumas substituições diferiram em tamanho, porém mantiveram alguns segmentos e o acento silábico da palavra-alvo. Essa descrição parece indicar que a dificuldade dessas crianças está no acesso à exata forma das palavras no léxico, apesar de o acesso aos padrões fonológicos mais abstratos, assim como ao detalhamento fonético fino se manter preservado.

Os resultados apontam também para o mesmo efeito de frequência de ocorrência dos itens lexicais encontrado por Swan and Goswami (1997), no qual 
todos os grupos - experimental e controle - obtiveram desempenhos piores no teste de nomeação de figuras para as palavras menos frequentes do que para as palavras de alta frequência. No entanto, nossos resultados não mostraram efeito de tamanho de palavra para os sujeitos disléxicos, o que difere dos resultados encontrados no estudo de Swan and Goswami (1997), no qual o grupo de disléxicos foi o único a apresentar tal efeito.

Os resultados anteriormente descritos sugerem, portanto, a confirmação da hipótese deste trabalho de que crianças com dislexia teriam um déficit específico na recuperação da forma sonora das palavras no léxico - mas não dos padrões fonológicos a respeito delas - sendo esse déficit no processamento da informação sonora a base da sua dificuldade em testes de nomeação de figuras.

\section{Referências}

ANDRADE, C. R. F. de. $A B F W$ : teste de linguagem infantil nas áreas de fonologia, vocabulário, fluência e pragmática. São Paulo: Pró-Fono, 2000.

BECKMAN, M. E.; MUNSON, B.; EDWARDS, J. The influence of vocabulary growth on developmental changes in types of phonological knowledge. In: COLE, J.; HUALDE, J. (Ed.). Laboratory Phonology 9, New York, Mouton de Gruyter, 2007. p. 241-264.

BOWEY, J. A. On the association between phonological memory and receptive vocabulary in five-year-olds. Journal of Experimental Child Psychology, v. 63, n. 1, p. 44-78, 1996.

BRADLEY, L.; BRYANT, P. Visual memory and phonological skills in reading and spelling backwardness. Psychological Research, v. 43, n. 2, 1981.

CAPOVILLA, F.C.; CAPOVILLA, A. G. S. Desenvolvimento linguístico da criança dos dois aos seis anos: tradução e estandardização do Peabody Picture Vocabulary Test de Dunn \& Dunn e da Language Development Survey de Rescorla. Ciência Cognitiva: Teoria, Pesquisa e Aplicação, v. 1, n. 1, p. 353-380, 1997.

CAPOVILLA, A.G. S.; CAPOVILLA, F.C. Problemas de leitura e escrita. São Paulo: Memnon, 2000.

DESROCHES, A. S.; JOANISSE, M. F.; ROBERTSON, E. K. Specific phonological impairments in dyslexia revealed by eyetracking. Cognition, 100, B32-B42, 2006.

DUNN, L. M.; DUNN, L. M. Peabody Picture Vocabulary Test: revised. 3rd ed. Circle Pines: American Guiadance Service, 1997. 
ESTEVES, C. O.; MAIA, M. A. R. Processamento da leitura e Acesso Lexical em Pacientes com Dislexia do Desenvolvimento. Revista Eletrônica JIC 29: Linguagem, Cognição e Sociedade. (No prelo)

FAUST, M.; DIMITROVSKY, L; SHACHT, T. Naming Difficulties in Children with Dyslexia:Application of the Tip-of-the-Tongue Paradigm. Journal of Learning Disabilities, v. 36, n. 3, 2003.

FERREIRA, A. A. Avaliação fonológica de crianças com distúrbio específico de linguagem sob a ótica da fonologia de uso. 2007. Dissertação (Mestrado em Linguística) - Faculdade de Letras da UFRJ, 2007.

LIBERMAN, I.Y.; SHANKWEILER, D.; FISCHER, F.W.; CARTER, B. Explicit syllable and phoneme segmentation in the young child. Journal of Experimental Child Psychology, v. 18, n. 2, p. 201-212, 1974.

MANIS, F. R.; McBRIDE-CHANG, C; SEIDENBERG, M.S.; KEATING, P.; DOI, L.M.; MUNSON, B.; PETERSEN, A. Are Speech Perception Deficits Associated with Developmental Dyslexia? Journal of Experimental Child Psychology, v. 66, n. 2, p. 211-235, 1997.

PIERREHUMBERT, J. Probabilistic phonology: discrimination and robustness. In: BOD, R.; HAY, J.; JANNEDY, S. (Ed.). Probabilistic linguistics. The MIT Press, Cambridge MA, 2003. p. 177-228.

RISPENS, J. Syntactic and phonological processing in developmental dyslexia. 2004. Tese (Doutorado em Linguística) - BCN (Behavioral and Cognitive Neurosciences) in Groingen, 2004. ISSN 0928-0030.

SERRANO, B. (s/d) Fixação de fonemas e palavras: trabalhando os fonemas e palavras. CD-ROM elaborado para terapia fonoaudiológica.

SILVA, T. C.; GOMES, C. A. Representações múltiplas e organização do componente linguístico. Forum Linguístico, v. 4, n. 1, p. 147-177, 2007.

SNOWLING, M. J. Phonemic deficits in developmental dyslexia. Psychological Research, p. 219-234, 1981.

STANOVICH, K. E.; SIEGEL, L. S. Phenotypic performance profile of children with reading disabilities: a regression-based test of the phonological-core variabledifference model. Journal of Educational Psychology, v. 86, n. 1, p. 24-53 745, 1994.

SWAN, D.; GOSWAMI, U. Picture naming deficits in developmental dyslexia: the phonological representations hypothesis. Brain and Language, v. 56, p. 334-353, 1997. 
Anexo 1

Pseudopalavras Utilizadas no Teste de Leitura de Pseudopalavras

\begin{tabular}{|l|l|l|l|}
\hline ZALA & VÍDACAS & HOVE & LEPEÇA \\
\hline TILA & CHEPALA & FOXE & GENICO \\
\hline DALÉ & CAVALHA & HIMO & XERIBE \\
\hline SEVA & VOPEGAS & CEFO & NEZEMA \\
\hline JILE & DEVALHA & LEÇO & FIGETA \\
\hline CHUDA & CHUDETA & SALIZ & CIPARRO \\
\hline
\end{tabular}

